\title{
Geographic atrophy with choroidal thinning following brilliant blue staining
}

\author{
Sumit Randhir Singh, ${ }^{1,2}$ Jay Chhablani ${ }^{2}$
}

'Retina and Uveitis Department, GMR Varalakshmi Campus, LV Prasad Eye Institute, Visakhapatnam, Andhra Pradesh, India

${ }^{2}$ Smt. Kanuri Santhamma Centre for Vitreo-Retinal Diseases, L V Prasad Eye Institute, Hyderabad, Telangana, India

\section{Correspondence to} Dr Jay Chhablani, jay.chhablani@gmail.com

Accepted 1 May 2019

\section{DESCRIPTION}

A 66-year-old woman presented with diminution of vision in her right eye for 1 year, with best corrected visual acuity (BCVA) of 20/125 . Left eye examination was within normal limits with a BCVA of 20/20. Spectral domain optical coherence tomography (OCT) showed a full-thickness macular hole in the right eye (figure 1) with a subfoveal choroidal thickness of $129 \mu \mathrm{m}$. The right eye underwent 23-gauge pars plana vitrectomy (Constellation; Alcon, Fort Worth, Texas, USA), with internal limiting membrane peeling using brilliant blue (BB) dye $(0.25 \mathrm{mg} / \mathrm{mL})$ staining under infusion and fluid gas exchange with $12 \% \mathrm{C} 3 \mathrm{~F} 8$. A xenon endoillumination light probe at $80 \%$ setting was used. At 1 month post surgery, the patient's BCVA improved to 20/80; however, at 6 months' follow-up, her BCVA deteriorated to finger counting at $1 \mathrm{~m}$. Fundus examination showed a large patch (threedisc diameter) of retinal pigment epithelium (RPE) atrophy involving the fovea with a corresponding hypoautofluorescent patch on autofluorescence imaging (figure 2). OCT showed marked atrophy of the RPE with loss of inner choroidal layers and a subfoveal choroidal thickness of $49 \mu \mathrm{m}$; OCT angiography choriocapillaris slab showed prominent medium choroidal vessels due to thinning and atrophy of RPE and choriocapillaris (figure 2).

Previous studies conducted on the effect of BB dye on RPE cells have proven it to be safe. ${ }^{12}$ However, few case reports have documented its toxic effect on RPE, including RPE hypertrophy
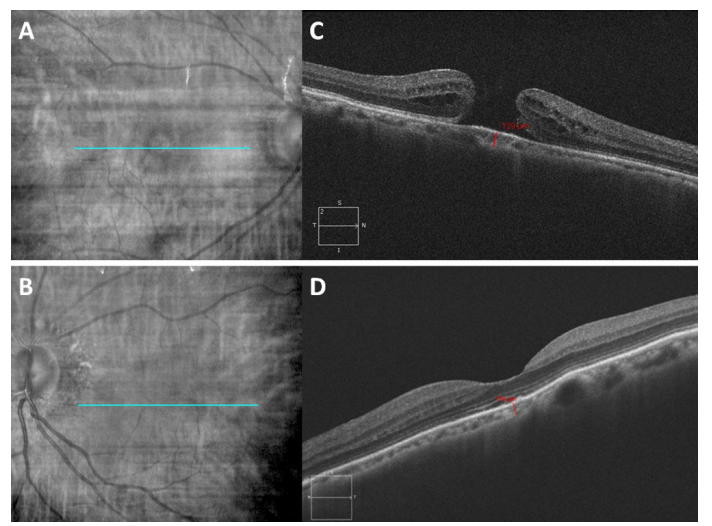

Figure 1 Multimodal imaging at presentation: infrared images $(A, B)$ of both eyes show a tessellated background. Spectral domain optical choroidal tomography of the right eye (C) shows a full-thickness macular hole and that of the left eye (D) shows a normal retinal contour. Subfoveal choroidal thicknesses is 129 and $103 \mu \mathrm{m}$ in the right and left eyes, respectively.

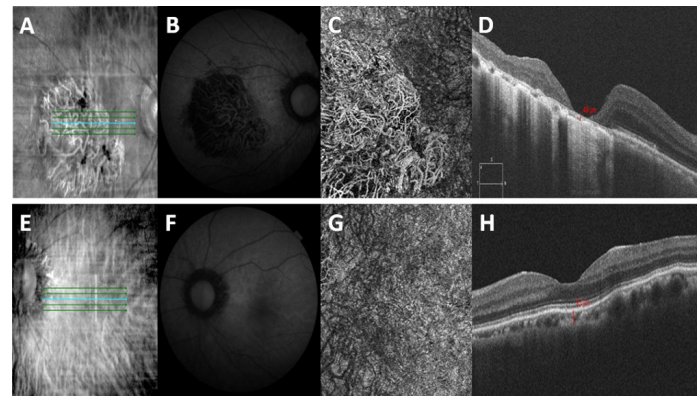

Figure 2 Multimodal imaging at 6 months following macular hole repair in the right eye: gross retinal pigment epithelium atrophy with visibility of large choroidal vessels noted on the infrared image (A), autofluorescence (B) and associated choriocapillaris loss on optical coherence tomography angiography $(C)$ of the right eye. Optical coherence tomography (D) of the right eye showed gross foveal thinning with choroidal thinning. Left eye images $(\mathrm{E}-\mathrm{H})$ appeared status quo as baseline. Subfoveal choroidal thickness was 49 and $93 \mu \mathrm{m}$ in the right and left eyes, respectively.

and hyperpigmentation. ${ }^{34}$ Interestingly, the present case shows extreme choroidal thinning with inner choroidal loss and gross outer retinal damage, which has never been reported earlier. There was no intraoperative evidence of subretinal migration of $\mathrm{BB}$ dye, which otherwise could have partly explained the chorioretinal damage.

Another differential diagnosis that merits consideration is phototoxic maculopathy due to operating microscope and endoilluminator. ${ }^{56}$ In this scenario, microscope-related phototoxicity is less likely due to limited exposure time. Endoilluminator-related toxicity is expected to create a round lesion, as suggested by Kweon et al, due to the round tip of the probe. ${ }^{6}$ Multiple factors are associated with phototoxic maculopathy, including surgical time, focus, blue wavelength light, fundus pigmentation and coexisting retinal vascular pathologies. ${ }^{56}$ Duration of surgery was less $(40 \mathrm{~min})$ compared with the average duration $(100 \mathrm{~min})$ reported in previous series. ${ }^{6}$ Moreover, lesions related to light toxicity appear superior or inferior to the fovea with relative sparing of the fovea due to concentrated xanthophylls at the fovea. ${ }^{6}$ Overall, this suggests a distant possibility of phototoxic maculopathy in our case.

\section{Patient's perspective}

My vision improved to a certain extent after surgery; however, it has further deteriorated over time. 


\section{Learning points}

Usage of brilliant blue dye in vitreoretinal surgeries is generally safe. Although rare, loss of retinal pigment epithelium (RPE) and choroidal thinning can happen in predisposed individuals.

- Phototoxic maculopathy is a close differential of dye-related chorioretinal toxicity presenting with a well-defined area of diffuse RPE atrophy.

A probable cause for such an extensive RPE damage and choroidal thinning could be the pre-existing choroidal thinning associated with a tessellated fundus. Whether the pre-exisiting choroidal thinning aggravates the dye toxicity is the question that needs further experiments and requires careful usage in such eyes.

Contributors SRS was involved in manuscript writing, image editing and preparing the revision of the manuscript. SRS and JC reviewed the article. JC was the treating physician. Both authors conducted the study and equally contributed in the preparation, review and approval of the manuscript.
Funding The authors have not declared a specific grant for this research from any funding agency in the public, commercial or not-for-profit sectors.

Competing interests None declared.

Patient consent for publication Obtained.

Provenance and peer review Not commissioned; externally peer reviewed.

\section{REFERENCES}

1 Creuzot-Garcher C, Acar N, Passemard M, et al. Functional and structural effect of intravitreal indocyanine green, triamcinolone acetonide, trypan blue, and brilliant blue $\mathrm{g}$ on rat retina. Retina 2010;30:1294-301

2 Morales MC, Freire V, Asumendi A, et al. Comparative effects of six intraocular vital dyes on retinal pigment epithelial cells. Invest Ophthalmol Vis Sci 2010:51:6018-29.

3 Jindal A, Pathengay A, Mithal K, et al. Macular toxicity following brilliant blue $\mathrm{G}$-assisted macular hole surgery - a report of three cases. Nepal J Ophthalmol 2014;6:98-101.

4 Saeed MU, Heimann H. Atrophy of the retinal pigment epithelium following vitrectomy with trypan blue. Int Ophthalmol 2009;29:239-41.

5 Charles $\mathrm{S}$. Illumination and phototoxicity issues in vitreoretinal surgery. Retina 2008;28:1-4.

6 Kweon EY, Ahn M, Lee DW, et al. Operating microscope light-induced phototoxic maculopathy after transscleral sutured posterior chamber intraocular lens implantation. Retina 2009;29:1491-5.

Copyright 2019 BMJ Publishing Group. All rights reserved. For permission to reuse any of this content visit https://www.bmj.com/company/products-services/rights-and-licensing/permissions/

BMJ Case Report Fellows may re-use this article for personal use and teaching without any further permission.

Become a Fellow of BMJ Case Reports today and you can:

- Submit as many cases as you like

- Enjoy fast sympathetic peer review and rapid publication of accepted articles

- Access all the published articles

- Re-use any of the published material for personal use and teaching without further permission

For information on Institutional Fellowships contact consortiasales@bmjgroup.com

Visit casereports.bmj.com for more articles like this and to become a Fellow 